Tropical Journal of Pharmaceutical Research April 2018; 17 (4): 687-693

ISSN: $1596-5996$ (print); 1596-9827 (electronic)

(C) Pharmacotherapy Group, Faculty of Pharmacy, University of Benin, Benin City, 300001 Nigeria.

\title{
Students' perceptions of the role of pharmacists in the healthcare system in Lahore, Pakistan
}

\author{
Imran Hameed Khaliq ${ }^{1 *}$, Farhan Hameed Khaliq ${ }^{2}$, Yaseen Abdullah ${ }^{1}$, Hafiz Zahid \\ Mahmood $^{3}$, Muhammad Danish Sarfraz ${ }^{4}$, Saeed Ahmad ${ }^{5}$, Shakila Zaman ${ }^{1}$ \\ ${ }^{1}$ Department of Public Health, University of Health Sciences, ${ }^{2}$ Hussain College of Health Sciences, ${ }^{3}$ Department of \\ Management Sciences, COMSATS Institute of Information Technology, Lahore, ${ }^{4}$ Department of Radiology, Shifa International \\ Hospital, Islamabad, ${ }^{5}$ Faculty of Pharmacy and Alternative Medicine, The Islamia University of Bahawalpur, Bahawalpur, \\ Pakistan
}

*For correspondence: Email: imranham90@gmail.com Tel: +923227171089

Sent for review: 18 October 2017

Revised accepted: 20 March 2018

\begin{abstract}
Purpose: To explore the role of pharmacists in the healthcare system of Lahore, Pakistan; and to determine association between students' socio-demographic indicators and the likelihood of consulting with a pharmacist.

Methods: In this exploratory study, data were collected from 589 students at a private sector university in Lahore, Pakistan, using a convenient sampling design. Information was collected using a semistructured questionnaire. Descriptive statistics (i.e., mean, standard deviation, percentages) and chi square were employed.

Results: Of 621 questionnaires, a total of 589 were returned, giving a response rate of $94.85 \%$. The results showed that 289 students (49.06\%) have interacted with pharmacists; however, the majority of the students $(98.64 \%)$ agreed there is a strong need for pharmacists who can provide guidance on medication safety. Furthermore, there was a statistically significant association between family system $\left(x^{2}(1)=4.046, p=0.004\right)$, age of family head $\left(x^{2}(1)=11.755, p=0.001\right)$, education level of family head $\left(x^{2}(1)=10.473, p=0.001\right)$, and consulting a pharmacist.

Conclusion: There are important roles for pharmacists to play in order to improve the healthcare system of Lahore, Pakistan. Some social demographics affect the likelihood that a person will seek professional counseling from a pharmacist.
\end{abstract}

Keywords: Medication safety, Healthcare system, Pharmacist consultation, Students' perception

\begin{abstract}
This is an Open Access article that uses a funding model which does not charge readers or their institutions for access and distributed under the terms of the Creative Commons Attribution License (http://creativecommons.org/licenses/by/4.0) and the Budapest Open Access Initiative (http://www.budapestopenaccessinitiative.org/read), which permit unrestricted use, distribution, and reproduction in any medium, provided the original work is properly credited.

Tropical Journal of Pharmaceutical Research is indexed by Science Citation Index (SciSearch), Scopus, International Pharmaceutical Abstract, Chemical Abstracts, Embase, Index Copernicus, EBSCO, African Index Medicus, JournalSeek, Journal Citation Reports/Science Edition, Directory of Open Access Journals (DOAJ), African Journal Online, Bioline International, Open-J-Gate and Pharmacy Abstracts
\end{abstract}

\section{INTRODUCTION}

Pharmacy is an ancient profession, responsible for overseeing the safe, effective and rational use of medicine. Pharmacists are the custodians of drugs and play a multi-dimensional role within different tiers of the healthcare system [1]. Pharmacists' operational practices vary between different countries [2]. Globally, pharmacists have emerged as important healthcare practitioners for the promotion of safe and rational utilisation of medicines [1]; they are 
expected to deliver pharmaceutical care while adhering to an integrated patient-pharmacist professional framework based on trust, caregiving, communication, cooperation and mutual decision making [3].

At present, in Pakistan, the pharmaceutical profession is evolving from a product-oriented approach towards one of patient-centered care. This transformation is exemplified by the upgrading of the 'Bachelor of Pharmacy' degree to 'Doctor of Pharmacy' in concert with the shift in pharmacists' focus from the manufacturing of drugs to clinical activities like patient education, solving drug-related problems, and monitoring of therapeutic regimens [4]. These changes are a positive sign for the mature development of Pakistan's health care system.

People aware of the actual role of a pharmacist believe that the profession is being taken over by physicians, who consider themselves to be the supreme authority in the healthcare system [5]. This impedes patients' ability to understand their therapies [5]. In Pakistan, retail pharmacy practices are still undersized owing to the scarcity of resources available to pharmacists in the current economy. As a result, this space has been occupied mainly by businessmen who establish and run retail drug stores [6].

Although there are multiple chain pharmacies in the country, they primarily operate as retail stores, and earn the name 'pharmacy' only by retaining an on-duty pharmacist who is generally not involved in counseling or prescription audits, but in the monitoring of drug sales. In this context, it is worthwhile to determine the perceptions of university students regarding the need for pharmacists in Pakistan.

It is important for patients to be well informed about the skills and capabilities of pharmacists, and how their services can add value to patients' quality of health beyond what physicians alone can provide. It is only then that pharmacies can evolve from product-oriented to patient-oriented practices [7]. To date, few studies have focused on students' perceptions regarding the need for pharmacists in the healthcare systems of developing countries such as Pakistan.

This study was therefore been conducted to explore current levels of doctor-patient interaction; student perceptions of the need for pharmacists in the health care system of Lahore, Pakistan; and to determine the association between students' demographic indicators and their visits to pharmacists for counseling.

\section{EXPERIMENTAL}

\section{Ethical approval}

The survey was approved by the Ethical Review Committee, Hussain College of Health Sciences/Hussain Memorial Hospital, Lahore (No. HCSC/18/ERC/101). Moreover, this study followed international ethical guidelines for health-related research involving humans [8].

\section{Study design and setting}

This exploratory study was conducted from November 2016 to January 2017, with mixeddiscipline university students enrolled in a private university in Lahore, the provincial capital of Punjab, Pakistan.

\section{Sample size and sampling technique}

As of November 2016, 6,314 students were enrolled in the target university for this study [9]. The minimum sample size needed to maintain a $5 \%$ margin of error, $95 \%$ confidence interval and $50 \%$ response distribution was calculated as 363 participants using a raosoft sample size calculator [10]. Of the 621 questionnaires distributed, 589 were returned by students, for a response rate of $94.85 \%$. Students were assessed using convenience sampling.

\section{Study instrument development}

A multi-disciplinary team of authors developed a semi-structured questionnaire based on relevant literature [11-13], and a discussion was held amongst a small focus group $(N=20)$ of students. The questionnaire was validated in 2 steps. First, it was sent to professionals at pharmacy institutes in Lahore, who were asked to provide their expert opinions on the different elements of the instrument with respect to importance, simplicity and relativity. Second, the survey instrument was pre-tested on 10 students to assess presentation, acceptability, and ease of understanding of the questions.

\section{Data collection}

Student participants were provided with questionnaires by the data collection team. Participants were also informed of the study's purpose. The instrument consisted of the following three parts:

\section{Demographic characteristics}

Nine survey items assessed students' demographic information. Students were asked 
to describe their age (in years), gender (male, female), pre-enrollment education (Intermediate/12th Standard, Graduate, PostGraduate/Doctorate), marital status (married, unmarried), family system (nuclear, joint), family size, age of family head (in years), education of family head (illiterate, literate with no formal education, high school/10th standard, intermediate/12th standard, graduate or above) and monthly household income (in Pakistani Rs.), respectively.

\section{Doctor-patient level of interaction}

Nine survey items assessed participants' level of interaction with their doctors. All variables were measured as dichotomous variables (yes, no) i.e. 'good doctor-patient relations', 'comfort level during doctor-patient communication', 'doctor provides sufficient time for consultation', 'doctor provides extra information regarding medications', 'doctor prescribes economical alternate medications', 'doctor provides guidance regarding side effects of medications', 'doctor guides about immediate precautionary measures for medication side effects', 'doctor guides about drug-drug or drug-food interactions', and 'doctor guides to adhere medications (especially antibiotic) therapy'.

\section{Student perceptions of the need for pharmacists in the health care system}

Six survey items explored the students' perceptions of the need for pharmacists in the Pakistani health care system. Information was collected as nominal variables (yes, no) i.e. 'ever experienced any side effects of medications', 'want to reduce the side effects of the medication on oneself', 'familiar with the adherence to medication therapy', 'do you seek advice of a person regarding medications', 'need of a person who guides well about medication safety in treatment', and 'do you know about pharmacist or clinical pharmacist'.

\section{Statistical analysis}

Data analysis was conducted using Statistical Package for Social Sciences software (SPSS version 21, SPSS Inc., Chicago, IL, USA). Descriptive statistics (i.e. frequency distribution, percentages, and measures of central tendency) were the primary analytical methods used. A chisquare test was used to assess correlations between demographic indicators and students' tendency to consult with pharmacists regarding medication. Statistical significance was accepted at $p<0.05$.

\section{RESULTS}

Among the participants, $62.1 \%$ of the university students were female, while $37.9 \%$ were male (Table 1). Students' ages ranged from 21 to 34 years $(M=23.93$ years; $S D=1.340)$. The students' educational profile included university graduates $(65.7 \%)$ followed by intermediate / $12^{\text {th }}$ standard students (31.9\%), with the lowest level of participation from postgraduate students $(2.4 \%)$. Almost all of the students were single $(99.2 \%)$ while more than two-thirds of them belonged to nuclear family systems (72 \%). Table 1 also identifies the average age of students' family heads, as well as their respective highest levels of education. The majority of family heads $(75.7 \%)$ were 51 years or older, and most $(41.9 \%)$ were highly educated.

Table 2 describes students' levels of doctorpatient interaction. The majority of the students $(83.02 \%)$ reported that they had not established good personal relations with their doctor. However, comfort levels during doctor-patient communication were reported to be sufficient by $84.89 \%$ of students. In response to two survey items, more than two-thirds $(78.10 \%)$ of students stated that their doctor provides them with sufficient time during consultation; a moderate number of students $(41.77 \%)$ agreed that their doctor provides them with more time to impart additional information regarding medication. Doctors' guidance related to side effects of medications was also assessed in this survey, and the majority of the students stated that their doctors never counseled them regarding side effects of medications $(80.65 \%)$ or measures to be taken in response to those side effects (83.36\%).

Table 3 presents students' perceptions of the need for pharmacists in Lahore's health care system. Nearly one-third of the students $(34.80$ $\%$ reported that they had experienced side effects from medications. Conversely, the survey item concerning self-health consciousness - i.e., students' desire to avoid the side effects of medications was the utmost need of most of the targeted students $(96.26 \%)$. Moreover, a significant number of students $(90.66 \%)$ expressed keen interest in receiving advice regarding medications, while a vast majority $(98.64 \%)$ endorsed the need for a designated person to provide pharmaceutical care and assistance to patients in hospitals. 
Table 1: Demographic information of student participants $(N=589)$

\begin{tabular}{|c|c|c|c|c|c|c|c|}
\hline \multicolumn{2}{|c|}{ Demographic characteristics } & $\mathbf{N}$ & $\%$ & Mean & Min & Max & SD \\
\hline Age (years) & & 589 & - & 23.93 & 21 & 34 & 1.340 \\
\hline \multirow[t]{2}{*}{ Gender } & Male & 223 & 37.9 & & & & \\
\hline & Female & 366 & 62.1 & & & & \\
\hline \multirow[t]{3}{*}{ Pre-enrollment education } & Intermediate/12th standard & 188 & 31.9 & - & - & - & - \\
\hline & Graduate & 387 & 65.7 & & & & \\
\hline & Post graduate/doctorate & 14 & 2.4 & & & & \\
\hline \multirow[t]{2}{*}{ Marital status } & Married & 5 & 0.8 & - & - & - & - \\
\hline & Unmarried & 584 & 99.2 & - & - & - & - \\
\hline \multirow[t]{2}{*}{ Family system } & Joint family system & 165 & 28.0 & & & & \\
\hline & Nuclear family system & 424 & 72.0 & - & - & - & - \\
\hline Family size & & 589 & - & 6.69 & 2 & 30 & 3.284 \\
\hline \multirow[t]{3}{*}{ Family head's age } & $31-40$ Years & 11 & 1.9 & & & & \\
\hline & $41-50$ Years & 132 & 22.4 & - & - & - & - \\
\hline & 51 Years and above & 446 & 75.7 & & & & \\
\hline \multirow{5}{*}{$\begin{array}{l}\text { Education of family } \\
\text { head }\end{array}$} & Illiterate & 17 & 2.9 & & & & \\
\hline & $\begin{array}{l}\text { Literate with no formal } \\
\text { education }\end{array}$ & 87 & 14.8 & - & - & - & - \\
\hline & High school/10th standard & 52 & 8.8 & & & & \\
\hline & Intermediate/12th standard & 186 & 31.6 & & & & \\
\hline & Graduate or above & 247 & 41.9 & & & & \\
\hline \multirow{5}{*}{$\begin{array}{l}\text { Monthly household } \\
\text { Income (Rs.) }\end{array}$} & $10,001-20,000$ & 6 & 1.0 & & & & \\
\hline & $20,001-30,000$ & 18 & 3.1 & - & - & - & - \\
\hline & $30,001-40,000$ & 59 & 10.0 & - & - & - & - \\
\hline & $40,001-50,000$ & 105 & 17.8 & & & & \\
\hline & Above 50,000 & 401 & 68.1 & & & & \\
\hline
\end{tabular}

Table 2: Doctor-patient level of interaction $(\mathrm{N}=589)$

\begin{tabular}{lr}
\hline Variable & $\begin{array}{c}\text { Yes } \\
\mathbf{n ~ ( \% )}\end{array}$ \\
\hline Good doctor-patient personal relations & $100(16.98)$ \\
Comfort level during doctor-patient communication & $500(84.89)$ \\
Doctor provides sufficient time for consultation & $460(78.10)$ \\
Doctor provides extra information regarding medications & $246(41.77)$ \\
Doctor prescribes economical alternate medications & $145(24.62)$ \\
Doctor provides guidance regarding side effects of medications & $114(19.35)$ \\
Doctor guides about immediate precautionary measures for medication side effects & $98(16.64)$ \\
Doctor guides about drug-drug or drug-food interactions & $95(16.13)$ \\
Doctor guides to adhere medications (especially antibiotic) therapy & $205(34.80)$ \\
\hline
\end{tabular}

Table 3: Students' opinions of the need for pharmacists in the health care system of Lahore, Pakistan $(\mathrm{N}=589)$

\begin{tabular}{lc}
\hline Variable & Yes \\
\hline Experienced any side effects of medications ever & 205(34.80) \\
Want to reduce the side effects of the medication & $567(96.26)$ \\
Familiar with the adherence to medication therapy & $212(35.99)$ \\
Do you seek advice of a person regarding medications & $534(90.66)$ \\
Need of a person who guides well about medication safety in treatment & $581(98.64)$ \\
Do you know about pharmacist or clinical pharmacist & $472(80.14)$ \\
\hline
\end{tabular}

\section{Association between students' socio- demographics and visit to pharmacist for medication consultation}

Table 3 compares male and female visits to pharmacists; females (50.3 \%) consulted pharmacists more often than did males $(47.1 \%)$. No statistically significant association was found between gender and the tendency to visit pharmacist for medication consultancy, $x^{2}(1)=$ $0.564, p=0.253$. Students' highest level of education $\left(x^{2}(1)=0.707, p=0.400\right)$ and monthly household income $\left(x^{2}(1)=1.219, p=\right.$ 0.270 ) did not significantly affect the tendency to consult with a pharmacist.

Table 3 further shows that in total affected the tendency to consult with a pharmacist. 
Table 4: Association between socio-demographics and tendency to consult with pharmacist

\begin{tabular}{|c|c|c|c|c|c|}
\hline \multirow[b]{2}{*}{ Demographic characteristics } & \multirow[b]{2}{*}{$\begin{array}{c}N(\%) \\
N=589\end{array}$} & \multicolumn{2}{|c|}{$\begin{array}{l}\text { Visit to pharmacist for } \\
\text { medication consultancy }\end{array}$} & \multirow[b]{2}{*}{$\begin{array}{c}\text { Chi- } \\
\text { Square } \\
\left(x^{2}\right)\end{array}$} & \multirow[b]{2}{*}{$\rho$ value } \\
\hline & & $\begin{array}{c}\text { No } \\
\mathrm{n}=300 \\
(\%)\end{array}$ & $\begin{array}{c}\text { Yes } \\
\mathrm{n}=\mathbf{2 8 9}(\%)\end{array}$ & & \\
\hline \multicolumn{6}{|l|}{ Gender } \\
\hline Male & 223(37.86) & $118(52.9)$ & $105(47.1)$ & \multirow{3}{*}{0.564} & \multirow{3}{*}{0.253} \\
\hline Female & $366(62.14)$ & $182(49.7)$ & $184(50.3)$ & & \\
\hline \multicolumn{4}{|l|}{ Highest Level of Education } & & \\
\hline Under-graduate and below & 188(31.9) & $91(48.4)$ & $97(51.6)$ & \multirow{2}{*}{0.707} & \multirow{2}{*}{0.400} \\
\hline \multicolumn{4}{|l|}{ Family System } & & \\
\hline Joint Family System & $165(28.01)$ & $95(57.6)$ & $70(42.4)$ & \multirow{3}{*}{4.046} & \multirow{2}{*}{$0.044^{*}$} \\
\hline Nuclear Family System & $424(71.99)$ & $205(48.3)$ & $219(51.7)$ & & \\
\hline \multicolumn{5}{|l|}{ Family head's age } & \\
\hline 50 years and below & $143(24.28)$ & $55(38.5)$ & $88(61.5)$ & \multirow{3}{*}{11.755} & \multirow{2}{*}{$0.001^{*}$} \\
\hline 51 years and above & $446(75.72)$ & $245(54.9)$ & $201(45.1)$ & & \\
\hline \multicolumn{5}{|l|}{ Education level of family head } & \\
\hline Illiterate & $104(17.7)$ & $38(36.5)$ & $66(63.5)$ & \multirow{3}{*}{10.473} & \multirow{3}{*}{$0.001^{*}$} \\
\hline Literate with formal education & 485(82.3) & $262(54.0)$ & $223(46.0)$ & & \\
\hline \multicolumn{4}{|l|}{ Monthly household income (Rs.) } & & \\
\hline 50,000 and below & $188(32.0)$ & $102(54.3)$ & $86(45.7)$ & \multirow{2}{*}{219} & \multirow{2}{*}{0.270} \\
\hline Above 50,000 & $401(68.0)$ & $198(49.4)$ & $203(50.6)$ & & \\
\hline
\end{tabular}

\section{DISCUSSION}

The results of the study showed that students were highly satisfied in terms of the interpersonal communication and consultancy time provided by their physicians. However, they were less satisfied with their physicians' guidance regarding many of their health-related concerns. The responses to the questionnaire reveal that physicians in Lahore seldom provide their patients with guidance regarding potential side effects of medication, or about measures to take when side effects occur. The students' level of health-consciousness was high, as nearly all of them showed serious concern about avoiding side effects from medication. However, nearly two-thirds of the students reported that they were unaware of medication therapy (especially antibiotics).

A majority of the participants believe there is a need for more pharmacists in the health care system. Students belonging to nuclear family systems were more inclined to consult a pharmacist for medication counseling than those from joint family systems. Students' family head ages and levels of literacy also affected their tendency to search for a pharmacist for counseling.

The results were consistent with a previous study conducted in Lahore which showed that physicians listened to patients' concerns actively (88 \%) while providing a comfortable environment (79\%) [14]. Moreover, these results were also comparable to other international studies; a study conducted in United States reported that up to $97.6 \%$ patients believed that they were given a comfortable atmosphere and privacy during examination [15], while one conducted in Brazil showed that patients had sufficient opportunity to ask their doctors questions and that they were highly satisfied [16]. However, contradictory results were obtained from a qualitative study conducted at University Hospital in Rio de Janeiro, Brazil, where the most frequent complaints were related to doctors' lack of attention, disinterest, lack of human warmth, and limited time devoted to consultation [17].

It is possible that physicians' counseling regarding the side effects of medication might be poorly received due to patients' limited understanding of directions for taking those medications [18]. Alternatively, it may be due to physicians' limited knowledge about certain drugs; pharmacology is taught as one major course of study during graduation, moreover, a physician mostly follows his peers for designing a therapy [19]. In this regard, the scenario in Pakistan is not so different from other developed and developing countries. In the United States, study showed similar results in which a small proportion $(14.0 \%)$ of patients were aware of common side effects of medication [20], while another study found that patients in India were poorly informed about which side effects may occur $(13.26 \%)$, how to recognise them $(5.68$ $\%)$, how long they are likely to continue (3.79\%), how serious they are $(6.06 \%)$ and what action should be taken (4.17\%) [21]. 
Situations where patients lack information about medication are generally observed to be due to a lack of counseling by a qualified pharmacist, or because the role of pharmacist is taken over by a dispenser (a category "C" holder) who has limited knowledge [22], in addition to being more concerned with selling drugs than with counseling patients. Moreover, pharmacy graduates of approved university and pharmacy assistants with category A and category B licenses, respectively, often rent them out to laymen possessing only a business background, and so take advantage of the license to operate a pharmacy in the community [23].

Regarding the nuclear family system, its members might be more likely to consult pharmacists, as family heads are more likely to make swift decisions about diseases and medications [24] owing to the limited number of family members; in the joint family system, decisions are influenced by peers and family elders based on their beliefs and experiences [25]. Similarly, regarding the association between literacy and visits to pharmacists, it is important to recognize that illiterate patients may have difficulty understanding spoken healthcare information because of the medical jargon and terminology used by physicians [26]. Such patients may therefore be especially interested in acquiring a better understanding of disease and its treatment, which is less prevalent among educated people because of their general awareness of medical therapies.

Finally, the effects of age can be linked to fitness and quality of life, as people under 50 are generally more energetic and productive and so wish to maintain their health, making them more concerned about their medication. In contrast, elderly people above 50 are more likely to acknowledge the inevitability of their physical degeneration, which reduces the likelihood that they will consult with a pharmacist [27].

\section{Limitations of the study}

Although this study provides valuable insights into the effects of socioeconomic indicators on the inclination to seek out a pharmacist for counseling, it does have some limitations. Owing to limited resources, only students at a privatesector university were surveyed. The experiences and socioeconomic profiles of students in other universities may differ. This study may be supplemented with possible future, larger-scale surveys in order to strengthen the conclusions drawn about public perceptions of pharmacists' roles in different healthcare systems.

\section{CONCLUSION}

The findings of this study indicate that students have some concerns regarding the information provided to them about their prescription medications. Additionally, socio-demographic indicators, including family system, family head's age and education level of family head, affect the likelihood that a patient would seek professional counseling from a pharmacist. Finally, there is a definite need for pharmacists to go beyond medication routine functions to engage in activities that reduce complications from side effects associated with medication use.

\section{DECLARATIONS}

\section{Acknowledgement}

The authors sincerely thank Khadija Amjad who supported in the proof-reading and content reviewing of the manuscript.

\section{Conflict of Interest}

No conflict of interest associated with this work.

\section{Contribution of Authors}

The authors declare that this work was done by the authors named in this article and all liabilities pertaining to claims relating to the content of this article will be borne by them.

\section{REFERENCES}

1. World Health Organization. Essential Medicines and Health Products Information Portal, 2017 [cited 2017 June 4]. Available from: http://apps.who.int/medicinedocs/en/d/Js2214e/2.html\#J s2214e.

2. Zheng JN, Hale K. Pharmacy Practice in Central and South America, 2015 [cited 2017 June 4]. Available from:

http://pharmacy.osu.edu/sites/default/files/forms/outreac h/intro2pharm/global-

practices/InternationalPharmacyPractice_Central-andSouth-AmericaZheng.pdf.

3. Li S, Azhar S, Murtaza G, Bin MHH, Asad SHS, Karim S, Shi C. Perception of Academic Pharmacists Towards Their Role in healthcare System of a developing Country, Pakistan: A Quantitative Sight. Acta Pol Pharm 2015; 72(2): 377-382.

4. Khan MU. A new paradigm in clinical pharmacy teaching in Pakistan. Am J Pharm Educ 2011; 75(8): 1. 
5. Mangasuli S, Rajan S, Khan SA. A decade of pharmacy practice education in India. Am J Pharm Educ 2008; 72(1): 1-3.

6. Azhar H, Ibrahim MIM. Medication counselling and dispensing practices at community pharmacies: a comparative cross sectional study from Pakistan. Int J Clin Pharm 2011; 33: 859-867.

7. Schommer JC. Patients' expectation and knowledge of patient counselling services that are available from pharmacists. Am J Pharm Educ 1997; 61(4): 402-406.

8. World Health Organization, and Council for International Organizations of Medical Sciences. International ethical guidelines for health-related research involving humans, 2016 [cited 2017 June 4]. Available from: https://cioms.ch/wp-content/uploads/2017/01/WEBCIOMS-EthicalGuidelines.pdf.

9. Higher Education Commission. University Wise Enrollment of Year 2014-15, 2017 [cited 2017 June 4]. Available from: http://www.hec.gov.pk/english/universities/Pages/Univer sity-wise-enrollment-of-yearwise.aspx.

10. Raosoft. An Online Sample Size Calculator, 2017 [cited 2017 June 4]. Available from: http://www.raosoft.com/samplesize.html.

11. McElnay JC, Nicholl AJ, Grainger-Rousseau TJ. The role of the community pharmacist-a survey of public opinion in Northern Ireland. Int J Pharm Pract 1993; 2(2): 95-100.

12. Stewart M, Brown JB, Boon H, Galajda J, Meredith L, Sangster M. Evidence on patient-doctor communication. Cancer Prev Control 1999; 3(1): 25-30.

13. Khan MU, Khan AN, Ahmed FR, Feroz Z, Rizvi SA, Shah $S$, Hussain R, Adil Z. Patients' opinion of pharmacists and their roles in health care system in Pakistan. $J$ Young Pharm 2013; 5(3): 90-94.

14. Mukhtar F, Anjum A, Bajwa MA, Shahzad S, Hamid S, Masood Z, Mustafa, R. Patient Satisfaction; OPD services in a Tertiary Care Hospital of Lahore. Professional Medical Journal 2016; 20(6): 973-980.

15. Cleary PD, Edgman-Levitan S, Roberts M, Moloney TW, McMullen W, Walker JD, Delbanco TL. Patients evaluate their hospital care: a national survey. Health Aff (Millwood) 1991; 10(4): 254-267.
16. Gouveia GC, Souza WVD, Luna CF, Souza-Júnior PRBD, Szwarcwald CL. Health care users' satisfaction in Brazil. Cad Saude Publica 2005; 21: 109-118.

17. Lemme AC, Noronha G, Resende JB. A satisfação do usuárioem Hospital Universitário. Rev Saude Publica 1991; 25(1): 41-46.

18. Jimmy $B$, Jose J. Patient medication adherence: measures in daily practice. Oman Med J 2011; 26(3):155-159.

19. The Institute for Operations Research and the Management Sciences. Peer influence among physicians affects repeat use of new prescription drug, INFORMS Marketing Science study finds, 2015 [cited 2017 June Available from: https://www.informs.org/About-INFORMS/News-

Room/Press-Releases/Peer-influence-amongphysicians-affects-repeat-use-of-new-prescription-drug

20. Makaryus AN, Friedman EA. Patients' understanding of their treatment plans and diagnosis at discharge. Mayo Clin Proc 2005; 80(8): 991-994.

21. Singh J, Singh N, Kumar R, Bhandari V, Kaur N, Dureja $S$. Awareness about prescribed drugs among patients attending Out-patient departments. Int J Appl Basic Med Res 2013; 3(1): 48-51.

22. DAWN. Unqualified people Running drugstores, 2003 [cited 2017 June 4]. Available from: https://www.dawn.com/news/100259.

23. Khan TM. Challenges to pharmacy and pharmacy practice in Pakistan. Australas Med J 2011; 4(4): 230235.

24. Rehman RR, Mobeen N. A Parent-Teacher View of Teens Behaviors in Nuclear and Joint Family Systems in Pakistan. Qual Rep 2014; 19(34): 1-12.

25. Segal UA. Cultural variables in Asian Indian families. Fam Soc 1991; 72(4): 233-241.

26. Graham S, Brookey J. Do patients understand? Perm J 2008; 12(3): 67-69.

27. Stewart TL, Chipperfield JG, Perry RP, Weiner $B$. Attributing illness to 'old age: 'Consequences of a selfdirected stereotype for health and mortality. Psychol Health 2012; 27(8): 881-897. 